\title{
On Unconditional Hos(ti)pitality: Thinking-doing Strategies for Dis/Abling Arts Education
}

Francisco B. Trento

The University of The Arts Helsinki

\section{DOI: https://doi.org/10.1344/jnmr.v2i1.33370}

\section{Abstract}

Hospitality and diplomacy are understood as universal hosting parameters. However, they fail to address non-neurotypical perception, jeopardising the inclusiveness of arts education environments. By bringing hospitality, inclusiveness, neurotypicality, and more-than-human wildness into conversation, I argue for developing pedagogical spaces oriented to deconstructing normalcy. This article emerges at the intersection of disability studies and neuroqueerness and it is further developed through Karen Barad's take on non-human agency and Deleuzoguattarian schizoanalysis. Jacques Derrida conceptualises hostipitality to problematise how hospitality cannot enable radical difference. I discuss this notion in dialogue with anecdotes from The Spaze, which is a schizoanalytical experiment and a procedural architecture oriented to nonneurotypicality developed at the Senselab. There, relationality is understood as always more-than-human. In this article, I furthermore examine how diplomacy's rhetoric excludes non-neurotypical perception by enacting what Félix Guattari names normopathy, namely, the privileging of linguistic patterns, human-to-human relationalities, and typical socialities. By discussing non-neurotypicality, I aim to queer rhetoric in arts education, diffracting Derrida's notion of hospitality to foreground the more-than-human relationality developed by Deleuzoguattarian and Baradian perspectives.

\section{Keywords}

Neuroqueerness; hos(ti)pitality; radical pedagogies; arts education; Senselab 


\section{Hos(ti)pitality: A Troubling Concept}

In the seminar Pas d'hospitalité, given on January the $17^{\text {th }}$ in 1996 , published as Of Hospitality (Derrida \& Dufourmantelle, 2000), the deconstructionist philosopher Jacques Derrida exposed the fragilities of the concept of hospitality, which he defined in a different essay as the "right of a stranger not to be treated with hostility when he arrives on someone else's territory" (Derrida, 2000, p. 5). Hospitality consists of two legal layers: the layers that the state imposes upon its citizens and visitors, and those that operate in the household. The implicit rules of hospitality are spectral. They become present in their absence. As Derrida (p. 10) puts it:

If we do not know what hospitality is, it is because this thing which is not something is not an object of knowledge, nor in the mode of being-present, unless it is that of the law of the should-be or obligation, the act of hospitality, the imperative of which seems moreover contradictory or paradoxical.

Hospitality moreover does an organisational job, and it is necessary for the maintenance of many societal ties. However, its conditions of operability privilege those who can successfully be read as functional, as capable of performing identities and behaviours adequate to each environment-whether a private home, an art class, a concert, or a museum. Attached to implicit conventions, hospitality subtly distributes the visiting bodies into specific spatial, gestural, and discursive coordinates. By doing so, it feeds a hierarchy of subject positionalities. Hospitality separates the ones that can behave in particular ways and the ones that still cannot-and may never-perform as neurotypicals. It stratifies the roles of the host and the visitor. Once arrived at a certain destination, one is received as "a friend, but on the condition that the host, the Wirt, the one who receives, lodges or gives asylum remains the patron, the master of the household, on the condition that he maintains his own authority in his own home" (Derrida, 2000, p. 4).

Hospitality thus demands performative gestures for the host and the visitor. Its manifestation happens before the arrival of the subject, before any identification in the threshold of a space; facing the doorbell, customs, or immigration officers. Thresholds include an environment's spatial arrangements, and these do not only refer to gated institutions opened with the right credentials. There are also symbolic and gestural 
thresholds, involving the necessity of complying with particular social cues that are generally taken for granted.

Imagine a situation where one does not perceive the contours of one's own bodywhere it starts, ends and where the room begins -in the same manner as the host. This fabulation may sound absurd, but it is an issue when discussing cosmologies and modes of perception that deviate from ableist, Western onto-epistemologies. In a neurotypical world, hospitality is always hostipitality, as fidgeting or avoiding eye contact is never welcomed. The implicit rules of hospitality regard its embedded hostility. The host holds the quality of being "between vigilance and welcome" (Kearney, 2019, p. 5). Not all bodies carry the same understanding of where one body ends, and another begins, for bodies are porous and subject to numerous affects. Derrida \& Dufourmantelle (2000, p. 123-125) address the contingent porosity of a body that opens itself to otherness whereby:

the stranger, here the awaited guest, is not only someone to whom you say 'come', but 'enter', enter without waiting, make a pause in our home without waiting, hurry up and come in, 'come inside', 'come within me', not only toward me, but within me: occupy me, take place in me, which means, by the same token, also take my place, don't content yourself with coming to meet me or 'into my home'.

If I were to follow a binary framework, I could contrast the visitor to the stranger. A visitor does not always have to prove their credentials when arriving, but somebody always verifies them even before their arrival. A stranger tends to cause distrust; the contingency of unknown subjectivity presents itself as risky. Somebody who stims, fidgets, or interferes with the typical environment by embodying a different-nontypical-gaze is immediately read as a stranger. "Anyone can come at any time and can come in without needing a key for the door. There are no customs checks with a visitation. But there are customs and police checks with an invitation" (Derrida, 2000, p. 14). Hospitality thus becomes a threshold or door. Discursive, spatial, and societal configurations bind hospitality, which needs to be stretched towards radical modalities of inclusiveness. We need to think of hospitality's constraints as capable of being reassembled. Intensive hospitality, which I understand as pushing all of its limits, involves the risk of dealing with the uncertainty that one's space may not retain the same physical, functional, and performative characteristics after the newcomer- 
human or non-human-arrives. It means embracing the potential queering of the space itself and facing its contingency. The space does not host-is immanently built with the one(s) that enter(s) it.

Under normal circumstances, the host and the visitor feel obliged to match their understandings of hospitality, diplomacy and its rhetorical constraints, and these constraints are defined by the hosting institution primarily as noise that interrupts the flow of a typical conversation, therefore excluding a range of relations and bodily activities from the field and the environment. While Derrida's approach to hostipitality is perhaps far too human, hostipitality is a concept that could be queered. We can appropriate its potential to detour/skew rhetorical situations by embracing modes of presentation beyond its all-too-human linguistic and rhetorical constraints. Educators need to take seriously what the autistic disability studies scholar Melanie Yergeau (2018, p. 31) claims as the wild more-than-human rhetoric of those not read as neurologically typical: "I want a rhetoric that tics, a rhetoric that stims, a rhetoric that faux pas, a rhetoric that averts eye contact, a rhetoric that lobs theories about."

Hostipitality deals with the tensions that arise from the politics/policies of fear affecting displaced communities, as it "is owed to the other as stranger. But if one determines the other as stranger, one is already introducing the circles of conditionality that are family, nation, state, and citizenship" (Derrida, 2000, p. 7). These are general attributes that exist on a macropolitical level. However, within the micropolitical milieu of daily life (Deleuze \& Guattari, 1987), hostipitality is expressed in several forms of the need to perform as able, deceitful bodies that defy the binary distribution of bodies in pairs like cisgender heteronormativity/genderqueerness and neurodiversity/neurotypicality. The neurotypical white, non-disabled male becomes the measure of all things: a flawless human. The necessity to overcome this model needs to be jointly developed with an overcoming of the above binary pairs' anthropocentrism, vouching for ethical modes of egalitarianism that focus on a pre-individual share. In terms of the vitalism of the philosopher and feminist theorist Rosi Braidotti (2006), this share refers to zoe or the flow of life in which the subject only exists as "a post-identity site, or an embodied and embedded entity, which exists in the interaction with a number of external forces and others, not all of them human, social or historical others"(Braidotti, 2006, p. 266).

The flaws of hospitality are rarely discussed when it comes to micropolitical questions, like setting up an environment open to non-normative body-minds. Many discourses 
do not recognise these marginalised bodies as righteous possessors of rhetorical tendencies; a common trope says that somebody who interacts without looking in the other's eyes is stuck in a small or isolated world. Such affirmations doubly reinforce human-centredness by reducing non-normative individuals to a dehumanised or animalised state. Yet uncanny non-normative and neurodiverse body/minds have radical potential for developing wild pedagogies.

\section{Dismembering Hospitality: Diplomacy and Neurotypicality}

Hospitality consists of multiple concepts and practices, and diplomacy is at its core. According to the Concise Oxford English Dictionary (2011, p. 404), the notion of diplomacy refers to "the profession, activity or skill of managing international relations," or "skill and tact in dealing with people." Yergeau (2018, p. 153) argues that "diplomacy is merely another kind of invitation, an opening through which only the few have means to enter." A diplomat acts as a mediator between different realms and communication relies on a common denominator. The task of the mediator is to build bridges between worlds, consisting of different languages, cosmologies, and modalities of seeing. This role implies the existence of an ontological gap between opposing sides; that there is a clear divide. Linguistic and non-linguistic patterns of behaviour are not seen as parts of the same continuum of expression. Working mostly with spoken or written words, the mediator builds a threshold of differential exclusion instead of navigating a continuum.

In arts and other educational environments, something is missing when spoken words are enforced as proof of participation, ignoring "intimacies and knowledges that exceed the eye-to-eye, that exceed the I-to-I, [...] the gay(ze), the queering of the field, reference and looking" (Yergeau, 2018, p. 211). That is why Yergeau (p. 154) affirms that "diplomacy is an allistic construct, one that is straightly configured so as to disinvite neuroqueer subjects." A typical example of diplomatic pre-negotiation happens when moving to another country. One is expected to learn the language of the host. This set of coordinates transduced to the neurotypical world is then attached to expected bodily postures, facial expressions, talkative mouths, and predictable movements that vary across different cultural settings. By bodies, I understand any body - so not merely the human body. The hosts must comply to "a right, a duty, an 
obligation, the greeting of the foreign other" (Derrida, 2000, p. 4) while one is hosting. One becomes a host in one's role as a guardian of the integrity of imagined cohesive space in terms of its materiality and the modes of sociality that are there enabled. Hospitality does not relate well with the contingent plasticity of subjectivity, its potential to become other, or change (with) the environment. Nevertheless, "to be considered diplomatic, one must behave, move, and communicate in prosocial, appropriative ways" (Yergeau, 2018, p. 151). Hostipitality chunks the contours of one's view towards the neurotypical categorisation of the world as different body-minds perceive it. Repetitive patterns and echolalia are understood as acts not capable of producing novelty or difference, but as elements that cut or avoid communication, which is recognised as solely linguistic.

To queer hostipitality, I employ a conceptual apparatus that problematises the boundaries of typical subjectivity. In an education environment, typicality refers to the capability of expressing oneself in loud and clear language and making eye contact. To queer this typicality, I mobilise the concept of neurodiversity as was done by the autistic academic activist movement that demanded the recognition of a multiplicity of modes of existence (Manning, 2012), particularly after the nineties. The movement gained influence with blogs, websites, and, later, YouTube channels. It presupposes neurological variations are one of/among many natural configurations of the human body and subjectivity that need to be understood as other modalities of difference (such as gender, race, and class) are. Neurodiversity advocates for the development of concepts around divergent experiences in and of the world by crafting a non-ableist onto-epistemology that does not rely on the definitions employed by pathologising medical discourses.

Neurodiversity does not come without criticism, however. Pier Jaarsma and Stellan Welin (2012) vouch for a narrow concept of neurodiversity that includes highfunctioning autistic subjects, but not those diagnosed as low-functioning. The autistic psychologist Jac den Houting (2019) points out that the kind of argument developed by Jaarsma and Welin strengthens the dichotomisation between low-functioning and high-functioning autists and does consider the internal variations and contingencies of every subject's condition. One individual can be successful in some tasks but not in others, and those particularities can change due to environmental, health, or social constraints. Also, that dichotomisation/classification can be used "to restrict access to 
support for those deemed 'high functioning' and to deny autonomy and agency to those deemed 'low functioning”' (den Houting, 2019, p. 273).

My understanding of neurodiversity resonates with what Félix Guattari referred to as normopathy, which he claimed as one of the worst pathologies of the last century. The philosopher Erin Manning (2012) recaps an anecdote told by Peter Pál Pelbart regarding one of his final meetings with Félix Guattari in 1990. It is publicly known that Guattari suffered from severe bouts of depression, and during one of these episodes at Clinique de La Borde in France, he was petrified. After having slept in his car during a trip from Paris to Cour-Cheverny, he could not utter a single word until the next day. To detour the discomfort that the situation had caused, Peter decided to go on a walk with his partner, but Félix followed them. The imbroglio unfolded when the three of them stopped in front of a pigsty - "I tried to converse with the pigs, using my limited knowledge of oinking. Slowly, the dialogue became more animated, and Guattari began to participate in the conversation. He laughed a lot, and he oinked a lot" (Pelbart as quoted by Manning, 2012, p. 488). On that day, the only conversation they had consisted of oinking (see Manning, 2012). Instead of squeezing the communication into the normophatic parameters, one must, like the characters in the narrative, embrace the richness of other modalities of expression, behaviour, and perception. Normopathy, which they were avoiding, is a term frequently used by Oury and later by Guattari. It refers to the constant unhealthy need to attach to normalcy and neurotypicality and its restrictive linguistic modalities of communication (Cf. Manning, 2012; Massumi, 2014).

The anecdote reinforces the choice of an understanding of neurodiversity that encompasses numerous neurological variations. It embraces not only autism, but dyslexia, borderline personality disorder, and schizophrenia. Broadly, neurodiversity refers to the tendencies of anyone that cannot fit into the neurotypical patterns, and neurodiversity should not stratify subjects into the labels of able or non-able. Following the bio-social model of disabilities (see Shakespeare, 2012), neurodiversity understands that physical spaces and societal structures, like university environments or art studios, are ableist. Their design privileges neurotypical perceptions of the world, rendering them uncomfortable for neurodiverse or disabled individuals in general. One must overcome an ableist framework that considers specific individuals as lacking the capabilities to make them able to thrive in society, understanding that "individuals are 
disabled by societal barriers to access and exclusion rather than by medical conditions" (Cutler, 2018, p. 195); and at the same time, avoiding the dangers of flattening all physical differences by overlooking the power relations-driven systems of discrimination and privilege.

To accept neurological variation as natural is not to affirm that the material conditions of the world cannot rely on scientific statements about the physical, biological, and chemical realms. The aim is not to moralise modes of existence and their biosocial origins, while not forcing them to adapt to neurotypical patterns of societal organisation. Yergeau (2018, p. 43) explains how a subject is never neurodiverse enough while at the same time the subject tends to be read as excessively neurodiverse, as "the concept of place is an infinite regress, akin to nesting dolls." The ontological separation occurs discursively_ "in the case of autism, we might consider allism to occupy one pole and autism to occupy the other, with the remainder of human neurology situated in the vast space in between. In such an expanse, where would we situate infinite points among the autism-allism (or self-other) continuum?" (p. 43). To some extent, similar mechanisms affect mostly every subject, since "neoliberal regimes of biocapital produce the body as never healthy enough" (p. 49). Neurodiversity lingers; it cannot be extirpated from a body-mind, despite the numerous approaches on changing non-typical behaviour (cf. Yergeau, 2018), but it queers and moves.

\section{Neuroqueer(ing) Hospitality}

Rhetoric is at the core of the ableist device, and the discourses based on common sense reproduce the Aristotelian notion that the human species is uniquely capable of mastering linguistic skills. Language is understood as a set of codified vocal or written syntaxes shared among communities. Many animals share semiotic signals, from sonars to skin colour variations and numerous corporeal signs that indicate volition, intention, and danger. Amongst humans who privilege consciousness many wonder if an individual or set of individuals who do not comply with neurotypical standards can retain rhetoric or a Theory of Mind-the capability to decipher another human's intentionality. 
Yergeau's Authoring Autism (2018) discusses how neurodiversity and gender nonconformism come together. The discourse of one of the most famous researchers of applied behavioural analysis Ole Ivar Løvaas - a discourse that by the way represents the only supposed scientific 'treatment' for autism—compared the 'disfunction' that is 'autism' with that of gender dysphoria. Løvaas collaborated in the infamous Feminine Boy Project, "a grant-funded project that used the science of behaviourism to correct the behaviour of 'gender-disturbed children' and restore their chances at a heterosexual, gender-normative future" (Roscigno, 2019, p. 6). According to Yergeau (2018), neurodiverse and genderqueer folks are not non-rhetorical but demi-rhetorical: they are bodies that trick language itself, plus the consensus on what it means to identify as a subject. Autism, like genderqueerness, must be understood as a negotiation between rhetorical and arhetorical worlds. When one enters a space designed as 'inclusive,' neurodiverse and genderqueer folks are expected to accept and follow the implicit guidelines of a neurotypical/ableist dispositive. Although acceptance and coexistence are undoubtedly necessary qualities, we still must wildly radicalise them. Here, we need to employ Yergeau's (2018, p. 31) queering refrain: "I want a rhetoric that tics, a rhetoric that stims, a rhetoric that [commits] faux pas, a rhetoric that averts eye contact." A rhetoric that oinks, as expressed in the tale on Guattari's oinking above mentioned (Manning, 2012).

Identity-based frameworks fail in addressing neuroqueer diversity. Such normative frameworks are often violently imposed on non-allistic subjects in educational and other spaces. Yergeau (2018, p. 120) argues that in such spaces non-allistic subjects are expected to undergo an impossible "recovery" from conditions that are not diseases. The result of this process is the flattening of subjectivities whereby "emphases on recovery have less to do with [the] loss of neuroqueerness and more to do with the covering of neuroqueerness with normalcy." As such, "passing" for or "being read as" able-bodied becomes an ideal to strive for in normative situations of diplomacy. In such situations, subjects must perform as neurotypicals to be accepted according to the implicit normative rules of diplomacy and hospitality, covering, when possible, their neuroqueer traits. Therefore, "neuroqueer identity is dissected into discrete behavioural units that parents [or teachers, counsellors, and therapists] have the opportunity to reinforce or extinguish" (Yergeau, 2018, p. 120). These measures aim to put together normophatic individuals to put it in Guattarian terms (see Manning, 
2012). Any institutional critique is incomplete if it denies that the setting of an art education class-or any other class, for that matter-implicitly carries normative/normalising behavioural units that one must mimic.

In educational settings, the behavioural units that need to be exterminated are stimming, clapping hands, coughing in situations of stress, biting, etc. This normalising process anchors the subject into fixed points of identity whereby the undesired identity is thoroughly cleansed and made unreachable/invisible (Deleuze \& Guattari, 1987). Neoliberal regimes provide subjects with a range of possible elements and traits that can be composed into a range of acceptable identities. The plethora of options for acceptably remixing one's self-identity gives the impression of fluid movements. Yet, when such identification options are taken on, they are revealed to consist of a violent jumping from one identity to another-and are thus not at all fluid nor transitory. This illusion of mobility disguises the fact that the path in between identities has been lost and obscured. 'Betweenity'1 is excluded from the process of being read or identified as it is deemed unnecessary and undesirable for fulfilling the rules of the hospitality of the neurotypical world. The act of performing as a neurotypical requires an amount of effort that is frequently exhausting.

Here I am not implying that the need for medical treatment must be disregarded. After all, healthcare is a crucial aspect of a neurodiverse individual's life. Rather, I am arguing for a scenario that includes the practising of unconditional hospitality and the application of a genuinely fluid framework that respects divergent modalities of neurodiverse presentation. In the academic and art fields, this implies creating spaces radically open to divergent subjectivities. I call forth post-qualitative inquiry's (St. Pierre, 2018) contribution of refusing subject/object and human/non-human binarisms to generate pedagogical and research environments that not only respect divergent tendencies but are constructed with them. To bypass the risks of falling into the trap of boosting radical hospitality with humanist tendencies, I focus on a Baradian (2003, 2007, and 2012) new materialist queering of the concept of hospitality.

\footnotetext{
1 "Brenda Brueggemann, in her work on deaf rhetoric/ic/s, refers to these between spaces, these crevices and elided openings, as 'betweenity'. Brueggemann's conception of identity, like much of the queer work in this book, moves away from demi-rhetorical notions of fixity, instead apprehending identity as 'a relational positioning' that is always in flux" (Yergeau, 2018, p. 177).
} 


\section{Diffracting Radical Hospitality ${ }^{2}$}

The post-deconstructionist philosopher and quantum physicist Karen Barad's (2003, 2007) understanding of agency is vital to the practices I propose to craft spaces oriented to non-neurotypical perception. While the Derridean (2000) conceptualisation of radical hospitality is key to the development of safer spaces, it is grounded on the idea of separability in between individuals and understands agency as foregrounding human-centredness. That is why I bring Barad's agential realism into play. Barad's take on the entanglement between the ethical, ontological and epistemological realms is influenced by Derrida's spectrology and the Levinasian Other since, as Evelien Geerts $(2016$, n. p.) explains, "the ethical for all three thinkers is instead related to the subject that is being interrupted in her/his actions and is all about reckoning with ghosts from the past, and the unexpected, the disjointed, and the what-could-happen." Levinas and Derrida are concerned with the ethics of the encounter with the Other. For Barad "otherness"-and hence the ethics of encountering it- "never comes from below or from above, but from within intra-actions between the world and its beings" (Geerts, 2016, n. p.). A Baradian (2007) take on the formal rules of hospitality and its neurotypical ableist constraints implies that they are also constructed in the intraactions of the event of meeting somebody-human or not-human, as the face of the Other can no longer be restricted to the face of a human being (see Geerts, 2016). This implies that otherness, the ethics of the encounter, and hospitality should be deconstructed through procedural propositions that value these ever-changing material-discursive reconfigurations.

Barad (2003, 2007, and 2014) deconstructs the paradigm of separability between singular entities by troubling the notion of an external agency. Inspired by quantum physics that postulates the unpredictability of the movement of particles as the spinning protons that jump from one point to another, Barad affirms that, on a quantum level, all matter is queer and wild. Matter is composed and recomposed through operations that defy linear causality. "Electrons are queer particles, mita' y mita'. They are particles. They are waves. Neither one nor the other. A strange doubling. A queer experimental finding" (Barad, 2014, p. 173). In this paradigm, the individual entities,

\footnotetext{
2 The idea of diffracting expresses the internal differences and superpositions emerging in a relation, and the otherness that sustains the argument of hospitality cannot be anymore though in terms of separability. Diffraction moves from "'breaking apart' to 'cutting together-apart,' from 'light within dark within light' to 'agential separability'” (Barad, 2014, p. 176).
} 
"are not separate determinately bounded and propertied objects, but rather are (entangled 'parts of') phenomena (material-discursive intra-actions) that extend across (what we commonly take to be separate places and moments in) space and time" (2012, p. 32). What produces difference-or differentiation-are the intra-actions that take place between phenomena. Barad (2007) argues that such intra-actions differ from Cartesian cuts because in such cuts, there still is an external subject acting upon an object. The subject, in this case a human being entering the art lab, moves the lab's furniture around, moulds a piece of clay, or fills the plastic pool with water. Typically, the relations that are valued in an academic and artistic environment are the ones that involve human-to-human connections. Even if an artist produces a piece with nonhuman materials, its value is only considered when there is an external human evaluation-in the form of a discursive uttering. An intra-action enacts an agential cut happening somewhere. The contingency of a given space refers to the queerness of matter itself. The agential cut is a "local resolution within the phenomenon of the inherent ontological indeterminacy. Crucially then, intra-actions enact agential separability - the local condition of exteriority-within-phenomena. Thus, differentiating is not a relation of radical exteriority, but of agential separability, of exteriority-within" (Barad, 2012, p. 32). Things and spaces do not pre-exist their entanglements.

Neurodiversity is tackled twice when I employ this Baradian agential realist framework to think of a shared space for artists and researchers. First, when it comes to neurodiverse perception and speaking from this fluid, ever-changing positionality itself. Second, a common trope regarding neurodiverse behaviour describes neurodiverse folks as if they lacked relationality: a simple search on autism on YouTube shows parents or friends of autistic people telling narratives repeating the same refrain: 'The child is stuck in their own small world, where they play with toys, animals or all sorts of thingies but do not interact with anybody.' These affirmations are entirely inadequate-conceptually and ethically_and reveal several misunderstandings. In these cases, relationality only seems to be valued if there is a human element at playand by a human, one means a subject that possesses a talkative mouth expressing clear language. Third, intra-actions, which produce difference by cutting things together-apart (see Barad, 2014), create identities not as stable categories, for "identity is a phenomenal matter; it is not an individual affair. Identity is multiple within itself; or rather, identity is diffracted through itself-identity is 
diffraction/différance/differing/deferring/differentiating" (Barad, 2012, p. 32), and space and time are shaped only inside of phenomena.

While Barad and Deleuzoguattarian philosophies differ, there are resonances for my argument regarding the hierarchisation of bodies in each and every space(time). An ontology of immanence, ${ }^{3}$ like the one Deleuze and Guattari (1988) and Barad (2003, 2007, and 2012) conceptualise, presupposes a one-world ontology (St. Pierre, 2018), as opposed to the transcendental model, conceptualised by for instance Derrida, which is characterised by the separation between discrete entities or categories, such as the human and the animal, the body and the spirit, and the male and the female. In an ultimate sense, the binary categories reproduce the Platonic distinction between the material and the ideal worlds -in the latter the objects and beings would perform their perfection, in comparison to the decaying world where human experience takes place. An ontology of immanence needs to be considered when building any environment that aims to undo the centrism of the able-bodied human, for it does not posits the human body as the actor of all actions: "neither the knower nor the known can be situated in advance of the occasion's coming to be-both are immanent to the field's composition" (Manning, 2016, p. 30).

\section{Is Space the Place?}

Following the issues engendered by the lack of knowledge on how to welcome such diverse subjectivities and the lack of practices that engage with non-human materialities' agency in the context of arts education, I focus on experiments to undo these constraints of normativity. It is challenging to create spaces that welcome neurodiverse body-minds. The conditions that enable their active participation vary in the context of each institution where legal means that facilitate access for nonneurotypical folks intersect with gendered, racial, and social inequalities. Even when

\footnotetext{
3 There are risks on bringing together a philosophy that enacts a plea for immanence-Deleuze and Guattari-and a transcendental approach-Derrida. The philosopher Daniel W. Smith discusses the divide between transcendence and immanence in the recent French philosophy, taking these philosophers as inheritors of these directions. For Smith (2012, $p$. 272), "one can call into question the status of the transcendental subject (the well-known theme of the 'death of the subject'): by appealing either to the transcendence of the other or to the immanent flux of experience itself." While the Deleuzoguattarian philosophy's univocity vouches that there is nothing superior or beyond Being itself (see Smith, 2012), Derrida inherits a tradition that, after Descartes, found transcendence in the Subject or the Ego in consciousness' immanence. Derrida and Levinas positioned transcendence in the Other/otherness, feeding Derrida's idea of différance. Smith summarises differences between these philosophers in terms of epistemology, ethics, and ontology, including a concept of desire fuelled by a primordial lack in the human subjectivity, what Deleuze and Guattari criticise in their schizoanalysis. Despite the differences, I propose to queer Derrida's concept of hostipitality by thinking otherness not exclusively as a human other and through transcendence but through immanent mutual inclusion (see Massumi, 2014).
} 
there are legal subsidies and material conditions like physical and semiotic accessibility, hospitality remains an allistic barrier to many neurodiverse subjects. The Wirt, the one that hosts (Derrida, 2000), in this case, is mostly the teacher capturingor trying to capture - the attention of the participants, instead of facilitating a dance of attention. Or as Manning (2012, p. 108) writes it: "[D]ancing-with the environment cueing. It is less being attentive-to than becoming in attention-with: the dance of attention is alive with the tendencies of a mobility that can only express itself through the future-forming interval of event-time."

The hospitality device includes spatial arrangements, such as for instance where one needs to look or point their senses to be able to achieve approval, as well as the distribution of the environment's materials. Traditional classrooms and art studios favour those who can bear face-to-face conversations and look into one another's eyes, even in more decentralised modes of distributing the bodies in a classroom, like circles or small workgroups. Evaluators do not recognise relations with the field (materials) as relations worthy of being valued, discussed, or cared about. It is an irresponsible mode of thinking; of lacking careful attention given to non-human materials and their agential capabilities.

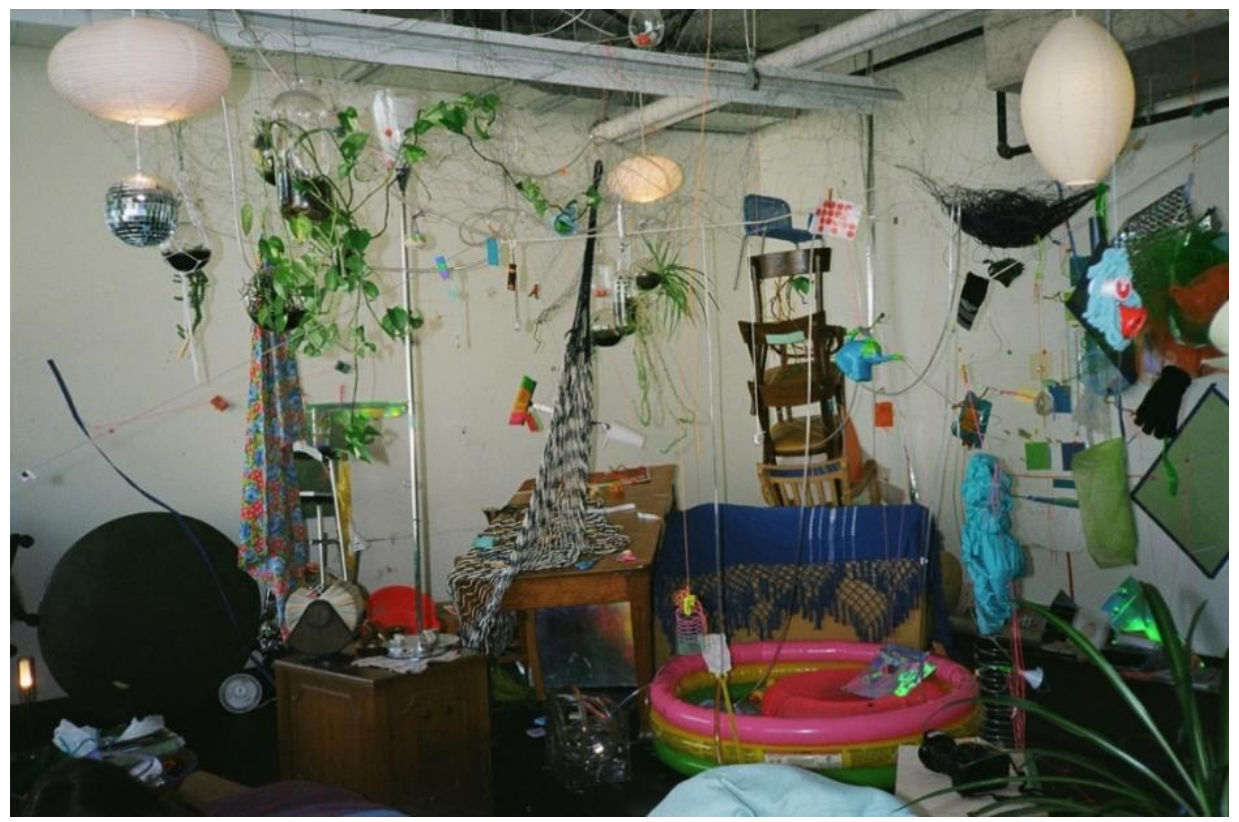

Figure 1: The Spaze: The iteration with the plastic pool (Trento, 2018) 
At Concordia University's Senselab-a laboratory of research-creation-a group of visual artists, philosophers and dancers have been trying to build a space radically open to neurodiverse bodies (see Manning and Massumi, 2014). The lab focuses on architectures that do not privilege face-to-face conversations and self-presentation, experimenting with a procedural structure. During the classes or reading groups, some individuals do not feel comfortable with situations that involve talking while looking into each other's eyes, targeted questions, and modes of participation that imply regular linguistic interactions. These tendencies are not universal for individuals that identify or are read as neurodiverse. I claim that all tendencies or traits must be not only considered but also co-implied when it comes to the production of a shared (a)sociality and its space(s).

After years of artistic and academic events, physical and digital archives populated the shelves of the research group's room at Senselab. While the topics discussed in the reading groups and classes in the Master of Fine Arts programme resonated with neurodiversity, individuals on the spectrum would rarely be present at the conversations-avoiding situations of discomfort, face-to-face discussions, personal presentations, and traditional forms of evaluation. The space allocated to Senselab used to be a room with a table, a bookshelf, and piles of documents. The residents started to gather the materials from past events that ranged from expensive art supplies to cheap plastic, and began to collectively reshape the room, as you can also see on Figure 1 on the previous page. It began as a fluctuating garden comprising glass terrariums attached to a net wire on the ceiling-the fence was previously part of an artwork by Erin Manning. Strong magnets allowed for connecting any material to the net with little effort.

Following years of composing, several iterations of the assemblage emerged: The Spaze-an assemblage embodying the concept of the anarchive, which is not a "documentation of past activity" (Senselab, 2016, n. p.) Derrida affirmed that "what remains unvanquished remains associated with the anarchive" (Ernst, 2015, p. 71). The anarchive, therefore, refers to what cannot be catalogued. In Senselab's understanding, the anarchive also does not refer to a stable entity or pile of categorised data. It is

a feed-forward mechanism for lines of creative process, under continuing variation, a cross-platform phenomenon, between media, between verbal and 
material expressions, between digital and off-line archiving, and most of all between all of the various archival forms it may take and the live, collaborative interactions that reactivate the anarchival traces, and in turn create new ones (Senselab, 2016, n. p.).

The anarchive embodied by The Spaze shifts the question from determining the nature of the material's identity to what it can do. The sensorial arrays of textures that the anarchival space propelled, were oriented toward non-neurotypical perception. However, there is not a goal or an idealised spatial configuration. On the contrary, the topology of the anarchival space must be procedural and immanent, resonating with the tendencies the shared appetites dictate. Sometimes, for example, the space needed to be divided up in smaller pieces, and everything was compacted in small and massive piles of things. In The Spaze, people can reconfigure the disposition of the objects by building new thresholds like tunnels, hiding places, pathways. Sessions of composing with the materials emerged according to everyone's personal appetites. Composing sessions always start in the middle, in the sense that there was never a formal call to action that orients what to do with the materials.

It is schizoanalysis that inspires the work done at the Senselab, or "the active operation that creates schisms, in an ecology of practices, opening up the event to its potential for a collectivity alive with difference" (Manning, 2016, p. 6). Schizoanalysis itself refers to a series of material-conceptual practices developed by Deleuze and Guattari (1987 and 2000) as a counterpoint to a Lacanian psychoanalysis which is on the idea of a primordial lack and the typically structured modus of taking language to be the source of the human unconscious. This Lacanian modus refers to "an individual oral performance, generally centred on a certain familialist habitus of subjectivity, in the context of developed industrial societies; [as well as] affective manifestations circumscribed in the etiolated space of the cure" (Guattari, 2012, p. 51). Contrary to this normalising modus, schizoanalysis, according to Guattari, "endeavours to mobilise collective and/or individual, subjective and/or objective formations, becomings human and/or animal, vegetable, cosmic... It will be directly involved in a diversification of the means of semiotization and will refuse any centring of subjectification" (p. 51). Schizoanalysis does not work upon the individual subject but on micropolitical transindividual assemblages of human and non-human bodies. 
The Spaze provides an answer to the micropolitical questions involving the different ways of perceiving and interacting with materials via schizoanalytical movement. While any assemblage is subject to the macropolitical shifts, The Spaze boosts absolute hospitality to an ecology of thingies that have their agency recognised-and this by not imposing how visitors need to engage with these materialities, and, mostly, by fostering care and radical hospitality with the non-human aspects of agency.

For Deleuze and Guattari (1988), micropolitical and macropolitical structures are intertwined. Micropolitics and macropolitics produce twofold categories, such as male/female, and human/animal through order words and distribution of the bodies in the societal realms. In the macropolitical, the binary classes are created by the great machines of binarisation. In contrast, in the micropolitical, these classes result from "multiplicities of $\mathrm{n}$ dimensions" (p. 212), and by doing so, they may dismantle the macropolitical stratified binary pairs. Following Deleuze and Guattari then, when one only tries to grasp an event by its macropolitical outcomes, one misses the germs of change that are developed by an event as an ongoing process.

The psychoanalyst Suely Rolnik vouches for the necessity of unceasing macropolitical and micropolitical insurrections. In a macropolitical insurgency, for instance, the agents are moved by "the urge to 'denounce' the injustices of the world in its current form, which tends to mobilise consciences" (Rolnik, 2017, p. 7). This movement is relevant to my argument because it is directed toward "empowering the subject," by freeing it from oppression and exploitation by moving beyond "the state of invisibility and inaudibility" (p. 7). This macropolitical insurrection operates by oppositions (oppressed/oppressor) through an ethico-political re-evaluation organised individually or via groups sharing identification (see Rolnik, 2017, p. 8). Rolnik thus brings Deleuzoguattarian vitalism into play by positing both human and non-human bodies as agents of the micropolitical insurrection. Bodies are stirred by "the impulse for perseveration of life, which, in humans, manifests as the impulse to 'announce' worlds to come" (p. 11). While the criteria for evaluation consists of achieving "what life demands to persevere every time it is weakened" (p. 11), cooperation takes place through the resonance and fabulation of embryonic worlds. In The Spaze, the thingies present are actants in an ever-changing ecology, despite being human-made or not, dead or alive. 


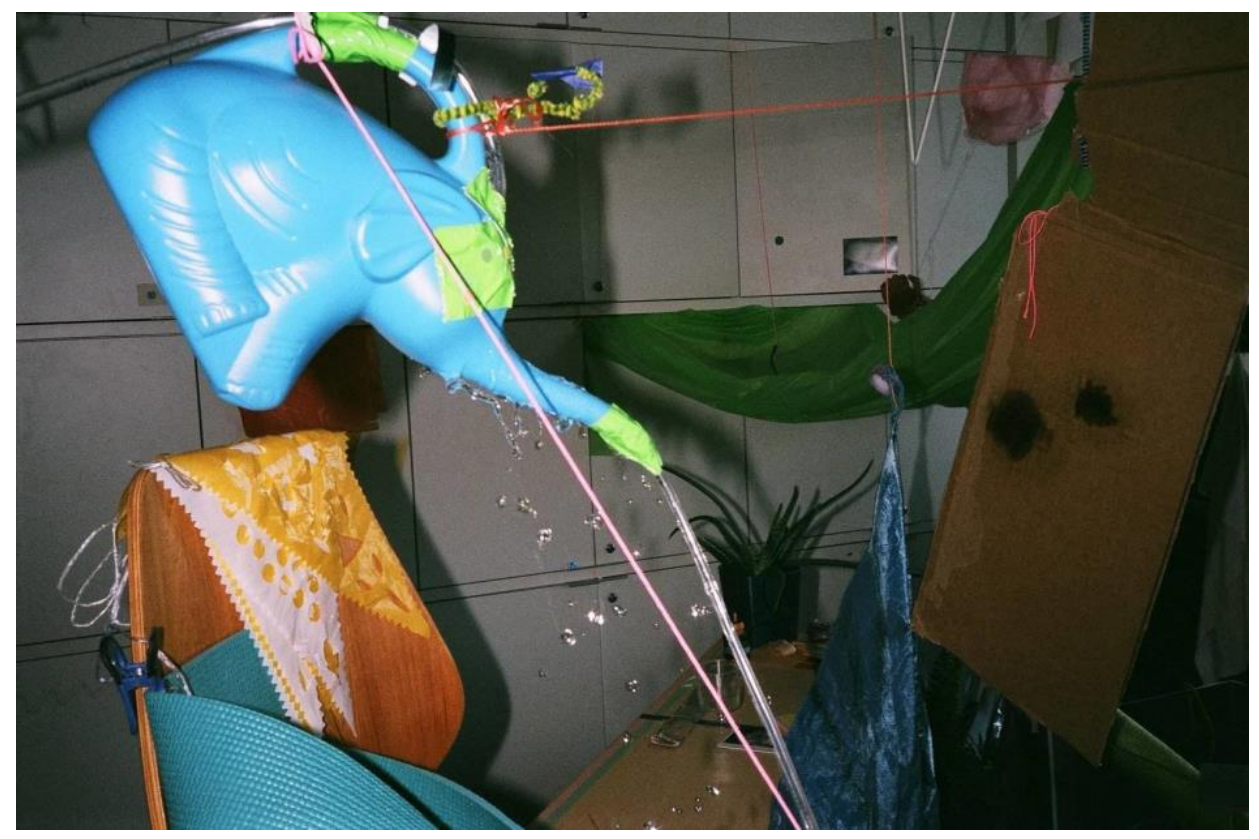

Figure 2: An ecology of thingies (Trento, 2018)

Dissent about the spatial configuration in The Spaze sometimes led to conflicts. Occasionally, I arrived at the lab, and somebody said that they did a favour 'cleaning the room' because the 'amount of overwhelming materials were creating discomfort during the classes and reading groups' due to the interference of the tunnels and caves that disrupted the office-alike qualities of the environment. The table resisted in its horizontality after many attempts to queer it, until the space reached a critical mass when the assemblage captured it permanently to a vertical configuration that made it unsuitable for labour. A rant kept on reverberating: 'The space is too crazy for people to work!' Such discourse reinforces the necessity of creating radically open spaces. Places and spaces that are already 'cleaned' and sterilised are extensively available in any other studying room of the university, or even at any café. This is not to mention the devaluation of material relational practices in favour of typical categories of working itself that takes place via such critique. The lack of proper care with these matters reaffirms that approaches oriented to neurodiversity only work if they promote mutual inclusion, are post-identarian, and, ideally, resist/work (against) disciplinary practices. There is a need for pedagogies oriented towards a collective transformative justice that denies linear causality centred on the subject of action towards the immanent building of truly fluid and cooperative environments, while considering the contingency that may generate uncomfortable situations. 
The Spaze works in terms of resonance, not mediation. If hospitality is charged with mediation-in the figure of the human moderator that translates one language to another-the resonance "connotes a bouncing a reverberating of modality against and between a mediating other" (Yergeau, 2018, p. 193). The set of techniques developed at The Spaze is not universal, nor automatically successful. Local techniques to enable neurodiverse socialities in the academic and artistic fields must be invented, paired with more institutional and legal forms of inclusion. Löytonen (2017, p. 7), for example, argues that differences cannot be represented but only palpated, and these differences express themselves in the event of the encounter between humans, their modes of being in the world, and non-human materialities. The wild palpations "follow (some) modes of thinking and working within the arts (e.g., experimentation, associativity, nonlinear mode of thought), and it is a methodological example of engaging and thinking in encounters, which might be developed and taken back to educational development processes" (p. 7).

While listing nine constraints for a radical pedagogy, Massumi (2017, p. 140), working within a Deleuzoguattarian framework, affirms that a wild pedagogy must "bring the situation to singular expression in a way that gives complete existence to the situation's real potential as potential, objectively infinite." Scholars, as Massumi (2017) and St. Pierre (2018) share in the necessity of making pedagogical interactions happen procedurally - the past events keep triggering new iterations of creation. Still, it is always possible to enter in the middle of these iterations. What are the required constraints on/for creating pedagogical environments that follow the ethics of an unconditional hostipitality? I would argue that they must be at least partially procedural: one must construct the space with the ones that are visiting-assuming that each mode of existing and seeing the environment has the same ontological status, dealing with possible conflicts and understanding that the majoritarian ways of composing societal structures are already ever-present in most western public and private spaces. Such wild pedagogical spaces must not reproduce the superiority of the 'correctly' spoken language. In academia, one is expected to speak using standardised language, as it is "produced in standardised forms by standardised subjects-while non-ableist people sign and stutter. We point and gesture and blink and blow and type. We have accents. We express ourselves through voices generated by computers and the bodies of others" (Ho et al., 2020, p. 131). Mixed methods of 
inquiry may come in handy. A wild pedagogy understands that pedagogical settings are always-in-construction, therefore allowing the expression of not-so-fixed betweenities.

\section{Seven Propositions for an Artistic Research Laboratory}

Many discussions about artistic-research pedagogies beyond fixed identities are currently being undertaken by venturesome wild pedagogues (see Manning, 2012 or Löytönen, 2017). Building upon these discussions and dialogues, I propose an approach to deal with non-human or non-neurotypical subjectivities, as academia evaluates relations only if they are understood as human-relations. To do so, one must follow Barad's (2003, p. 805) understanding of intra-action:

Phenomena are produced through agential intra-actions of multiple apparatuses of bodily production. Agential intra-actions are specific causal material enactments that may or may not involve 'humans.' Indeed, it is through such practices that the differential boundaries between 'humans' and 'nonhumans,' 'culture,' and 'nature,' the 'social,' and the 'scientific' are constituted.

The evaluation itself needs to change (Massumi, 2017), and spaces need to be radically opened up to all modes of perception. Mixed epistemologies and hybrid postqualitative methodologies moreover must be implemented. To sum it all up, here are a few propositions, which I have developed more extensively elsewhere (see Trento, 2020):

\begin{tabular}{|l|l|}
\hline 1) A procedural and contingent space. & $\begin{array}{l}\text { The materials that compose the } \\
\text { environment can be freely reassembled. }\end{array}$ \\
\hline $\begin{array}{l}\text { 2) A laboratory for invention—of new } \\
\text { modes of sociality. }\end{array}$ & $\begin{array}{l}\text { By incentivising participation that does } \\
\text { not rely on the requirement of a written } \\
\text { or formal outcome; for playing with a } \\
\text { textile thread or merely staying still } \\
\text { during an event is also a modality of } \\
\text { participation. }\end{array}$ \\
\hline
\end{tabular}




\begin{tabular}{|c|c|}
\hline $\begin{array}{l}\text { 3) The laboratory is a space for crash- } \\
\text { testing onto-epistemological concepts, } \\
\text { and concepts are machines. }\end{array}$ & $\begin{array}{l}\text { Think together how native concepts } \\
\text { problematise the normative and } \\
\text { functionalistic approaches to } \\
\text { marginalised subjectivities; not by } \\
\text { tokenising them but by employing them } \\
\text { as activators for social change. }\end{array}$ \\
\hline $\begin{array}{l}\text { 4) To facilitate the conceptualisation of } \\
\text { new futures-rethinking past and } \\
\text { presenting-by critically questioning our } \\
\text { perceptions and subjectivities. }\end{array}$ & $\begin{array}{l}\text { How to imagine the arts university in ten } \\
\text { years? Instead of merely focusing on } \\
\text { the productivism of scholar publishing, } \\
\text { to organise modalities of participation } \\
\text { that make the arts community more } \\
\text { inclusive and open to slower or non- } \\
\text { normative knowledge(s). }\end{array}$ \\
\hline $\begin{array}{l}\text { 5) To disrupt neurotypical perception, } \\
\text { spatially, discursively, and rhetorically. } \\
\text { And the rhetoric is more-than words. }\end{array}$ & $\begin{array}{l}\text { Instead of reproducing the models of } \\
\text { spatial organisation that have proven to } \\
\text { be valid for specific body-mind } \\
\text { configurations, facilitate other ways of } \\
\text { populating the university and art } \\
\text { institutions. }\end{array}$ \\
\hline $\begin{array}{l}\text { 6) To promote practices that dissolve } \\
\text { the boundaries between the able and } \\
\text { the disabled, the sane and the mad, the } \\
\text { human and the non-human. }\end{array}$ & $\begin{array}{l}\text { Respecting asymmetric power relations } \\
\text { and facilitating the necessities of } \\
\text { marginalised body-minds and creating } \\
\text { an environment where each body's } \\
\text { affordances can be performed in a non- } \\
\text { hierarchised way, where the human and } \\
\text { the non-human are valued; and where } \\
\text { any non-typical traits are appreciated. }\end{array}$ \\
\hline
\end{tabular}




\begin{tabular}{|l|l|}
\hline & $\begin{array}{l}\text { Conflicts will emerge in any scenario } \\
\text { populated with a diversity of modes of } \\
\text { existence. They require the employment } \\
\text { of immanent techniques of conflict- } \\
\text { hospitality. }\end{array}$ \\
$\begin{array}{l}\text { solving through non-punitive justice, and } \\
\text { not by excluding one who has } \\
\text { "inadequate" behaviour from } \\
\text { participation. }\end{array}$ \\
\hline
\end{tabular}

Table 1: Propositions

The suggestions sketched out above offer a multi-layered approach to absolute hospitality in artistic, pedagogical environments. The risks of hostipitality, as Derrida (2000) expressed, need to be considered, in conjunction with a queering of hostipitality beyond the boundaries of the human. That is why I employed a post-deconstructionist Baradian approach that recognises the intra-actions between human and non-human entities. Likewise, as Derrida's notion of hostipitality needs to be further queered towards the inclusion of non-linguistic modalities of rhetoric, Yergeau's comprehension of rhetoric recognises the devalued non-talkative patterns of language. Because of this, micropolitics in my regard seems fundamental for establishing pathways to avoid the normopathy in the classroom, and that by valuing the non-human and non-talkative relationalities as creative agents.

\section{Bibliography}

Barad, Karen (2003). Posthumanist performativity: Toward an understanding of how matter comes to matter. Signs: Journal of Women in Culture and Society, 28(3), 801831. https://doi.org/10.1086/345321.

Barad, Karen (2007). Meeting the universe halfway: Quantum physics and the entanglement of matter and meaning. Duke University Press.

Barad, Karen (2012). Nature's queer performativity. Kvinder, Køn \& Forskning, 1-2, 25-53. https://doi.org/10.7146/kkf.v0i1-2.28067.

Barad, Karen (2014). Diffracting diffraction: Cutting together-apart. Parallax, 20(3), 168-187. https://doi.org/10.1080/13534645.2014.927623. 
Corsín Jiménez, Alberto (2013). Introduction. Journal of Cultural Economy, 7(4), 381398. https://doi.org/10.1080/17530350.2013.858059.

Cutler, Emily Sheera (2018). Listening to those with lived experience. In S. Steinhard, Critical psychiatry: Controversies and clinical implications (pp. 179-206). Springer. https://doi.org/10.1007/978-3-030-02732-2 8.

Deleuze, Gilles \& Guattari, Félix (1987). A thousand plateaus: Capitalism and schizophrenia. (B. Massumi, Trans.). University of Minnesota Press. Originally published in French 1980.

Deleuze, Gilles \& Guattari, Félix. (2000). Anti-Oedipus: Capitalism and schizophrenia (R. Hurley, M. Seem \& H. R. Lane, Trans). Continuum. Originally published in French in 1972.

Den Houting, Jacquiline (2019). Neurodiversity: An insider's perspective. Autism, 23(2), 271-273. https://doi.org/10.1177/1362361318820762.

Derrida, Jacques, \& Dufourmantelle, Anne (2000). Of hospitality: Anne Dufourmantelle invites Jacques Derrida to respond. (R. Bowlby, Trans.). Stanford University Press.

Derrida, Jacques (2000). Hostipitality. (B. Stocker \& F. Morlock, Trans.). Angelaki, 5(3), 3-18. https://doi.org/10.1080/09697250020034706.

Ernst, Wolfgang (2015). Stirrings in the archive: Order from disorder. (A. Sigel, Trans). Rowman \& Littlefield.

Guattari, Félix (2012). Schizoanalytic cartographies. (A. Goffey, Trans.). Bloomsbury. Originally published in French in 1989.

Geerts, Evelien (2016, August 16). Ethico-onto-epistem-ology. New Materialism Almanac. Retrieved from http://newmaterialism.eu/almanac/e/ethico-onto-epistemology.

Ho, Ai Binh T., Kerschbaum, Stephanie L., Sanchez, Rebecca, \& Yergeau, Melanie (2020). Cripping neutrality: Student resistance, pedagogical audiences, and teachers' accommodations. Pedagogy 20(1), 127-139. Retrieved from https://www.muse.jhu.edu/article/746057.

Kearney, Richard (2019). Double hospitality. Journal for Continental Philosophy of Religion, 1(1), 71-89. https://doi.org/10.1163/25889613-00101005.

Jaarsma, Pier, \& Welin, Stellan (2011). Autism as a natural human variation: Reflections on the claims of the neurodiversity movement. Health Care Analysis, 20(1), 20-30. https://doi.org/10.1007/s10728-011-0169-9.

Löytönen, Teija (2017). Educational development within higher arts education: an experimental move beyond fixed pedagogies. International Journal for Academic Development, 22(3), 231-244. https://doi.org/10.1080/1360144x.2017.1291428. 
Manning, Erin (2016). The minor gesture. Duke University Press.

Manning, Erin (2017). In the act. In P. de Assis \& P. Giudici (Eds.), Dark precursor: Deleuze and artistic research (pp. 488-509). Leuven University Press. https://doi.org/10.2307/j.ctt21c4rxx.50.

Massumi, Brian (2014). What animals teach us about politics. Duke University Press.

Massumi, Brian (2017). The principle of unrest: Activist philosophy in the expanded field. Open Humanities Press.

McDougall, Joyce (1992). Plea for a measure of abnormality. Routledge.

Rolnik, Suely (2017). The spheres of insurrection: Suggestions for combating the pimping of life. E-flux, 86. Retrieved from https://www.eflux.com/journal/86/163107/the-spheres-of-insurrection-suggestions-for-combatingthe-pimping-of-life/.

Roscigno, Robin (2019). Neuroqueerness as fugitive practice: Reading against the grain of applied behavioral analysis scholarship. Educational Studies, 55(4), 405-419. https://doi.org/10.1080/00131946.2019.1629929.

Senselab (2016). Anarchive: A concise definition. Retrieved from https://senselab.ca/wp2/immediations/anarchiving/anarchive-concise-definition/.

Shakespeare, Tom (2012). Still a health issue. Disability and Health Journal, 5(3), 129131. https://doi.org/10.1016/j.dhjo.2012.04.002

Smith, Daniel W. (2012). Jacques Derrida: Deleuze and Derrida, immanence and transcendence: Two directions in recent French thought. In Essays on Deleuze (pp. 271-286). Edinburgh University Press. Retrieved from http://www.jstor.org/stable/10.3366/j.ctt3fgqq7.21.

Stevenson, Angus \& Waite, Maurice (2011). Concise Oxford English Dictionary (12th ed.). Oxford University Press.

St. Pierre, Elizabeth A. (2018). Post qualitative inquiry in an ontology of immanence. Qualitative Inquiry, 25(1), 3-16. https://doi.org/10.1177/de1077800418772634.

Trento, Francisco B. (2020). A procedural space for failure. Research in Arts \& Education, 2020(2), 1-22. Retrieved from http://urn.fi/URN:NBN:fi-fe2020072447600.

Yergeau, Melanie (2018). Authoring autism: On rhetoric and neurological queerness. Duke University Press. 


\section{Author Information}

\section{Francisco B. Trento (francisco.trento@uniarts.fi)}

Francisco B. Trento is a postdoctoral researcher at The Center for Educational Research and Academic Development in the Arts (CERADA) at UniArts Helsinki, Finland, and previously obtained a Ph.D. in Communication and Semiotics at Pontifícia Universidade Católica de São Paulo, Brazil. Their work emphasises nonneurotypical modes of perception and techniques for dis/abling the arts education through artistic research. Francisco previously worked as a postdoctoral researcher at the Senselab (Concordia University), and they work on the intersections between queer studies, post-qualitative inquiry, and critical disability studies. 